Mahmud E. Hajizada

DOI: 10.25045/jpis.v06.i2.08

Institute for Scientific Research on Economic Reforms under the Ministry of Economy and Industry, Baku, Azerbaijan

mahmud@hajizada.com

\title{
FACTORS OF INFORMATION SOCIETY FORMATION AND DEVELOPMENT TRENDS IN AZERBAIJAN
}

The article analyzes the stages of building the information society, the concept, formation factors and its development tendency in Azerbaijan. It is substantiated that, supplied by information revolution information society develops on the basis of the economic relations. Its development factors are the information infrastructure and culture, business and economic environment, the government, business organizations, civil society, electronic leaders in the synthesis of science and education. Certain generalizations based on analysis and assessments related to the information society are made demonstrating that Azerbaijan paid special attention to the development of the information society and its development is defined as a priority. Significance of the concept of "Azerbaijan 2020: Vision for the Future" associated with the development of non-oil sector is estimated.

Key words: information society, information economy, information and communication technologies, e-government, the economy of Azerbaijan.

\section{Introduction}

There have been several historical revolutions related to information and its processing. The first revolution in this chain is associated with the emergence of the culture of writing and the expansion of its transmission by generations. The social progresses related to the development of publication of books in the XV century is the second revolution. The following revolutionary event was the invention of electricity, telegraph, telephone, radio and so on, which could collect and transfer huge amount of data promptly. Invention of micro-processes and invention of personal computers in the 70s of the XX century led to the information technology revolution. Passing through the phase of technical and technological progress this revolutionary process gave an impetus for the emergence of certain theory and the development of a society, where majority deals with information production, storage, processing and realization, and particularly, with knowledge.

Now, transition to an information society accompanied by the widespread introduction of information technology is obvious. And communication is a key element and driving factor of information society. In fact, transition to an information society is manifested in various forms basing on its development level in different countries.

In this regard, information society formation and its development trends in Azerbaijan contain exceptional factors and features. Note that this formation and development is affected by the achievements and globalization trends of different countries in this field. In addition, strengthening own intellectual and technological grounds different countries show a number of distinctive characteristics and development trends of the information society formation. In such situation, new local formation factors occur. Numerous concepts of emergence factors and development properties of the Information society have already been developed so far and frequently perfected. In this regard, in Azerbaijan the development and formation characteristics of the information society should be analyzed in the context of global trends and related concepts. The article analyzes and evaluates the formation stages of the information society, its concepts, resource potential, information and communication technologies, digitization of the services, e-government phenomena, and development trends of the information society formation in Azerbaijan. 


\section{The development stages, concepts and resource potential of the information society}

The growing volume of information was more distinctive particularly in the middle of the XX century. Since the start of the excessive information flow caused some limits in being perception by the people. Growing and changing day by day this flow became more difficult to be penetrated. This inevitable and necessary process created crisis situations, and in turn, stimulated the creation of new intellectual products. The application of electronic-processing machines became the basis for the new evolutionary process named "informatization". In general, the informatization of the community as a whole has been closely linked with the satisfaction of the socio-economic demands and the development of scientific-technical progress formed on this basis $[1,2]$.

The establishment of the information society has led to the formulation of specific theories and concepts. American economist Fritz Machlup (1902-1983) and Japanese sociologist Tadao Umesao (1920-2010) stand in the front row of theoretical basics. Thus, the concept of "information society" was first defined in the US and Japan at the same time. Later, the concept was developed by Japanese futurologist and sociologist Yoneji Masuda (1905-1995), American economist Marc Porat (1932), English scientist Tom Stoner (1929) and others. Depending on the level of development of techniques and technology, the economic systems' division was carried out by American economists John Galbraith (1908-2006), Simon Kuznets (1901-1985), French economists and sociologists Raymond Aron (1905-1983) and Alain Touraine (1925), as well as other well-known economists. The US sociologists Daniel Bell (1919-2011), Walt Rostow (1916-2003) and Alvin Toffler (1928) brought some theoretical values and classified the economic systems as pre-industrial, industrial and post-industrial [3-6].

The stage of Pre-industrial society is also called "traditional" or "agricultural" due to the fact that in this system, economic production activities mainly include extraction of mineral resources, agriculture and fishery. In this public sector the main manufacturer is not a man, but the nature itself. It should also be noted that the economic systems aged thousands of years is the most sustainable society. It is still maintained in most countries of Africa, Latin America and Southeast Asia.

In the industrial society, which is the next phase of economic systems, all the forces are directed to the industrial production to produce necessary goods. The formation of this society is closely connected with the urbanization processes, establishment of a market economy, emergence of the social groups of employers and employees. Note that the term "industrial society" was first used in the studies by the French philosopher Saint-Simon (1760-1815) [17].

In the current post-industrial society, which is a new form of economic systems, industry lags behind the services sector for employment measures and the share of GDP. And in information processing is dominating in the service sector. The quality of postindustrial society is measured by its employees' level of education, professionalism, learning abilities and creativity. The concept of Postindustrial society was founded by D.Bell. In the book The Future postindustrial society published in 1973 , he gave a broad interpretation of the concept, and analyzed its main trends of changing the relations between the sectors of social production, the emergence of a service economy, the formation of scientific knowledge as an element of productive forces. The concept of Postindustrial society occurred when it was found out that American capitalism was different from industrial capitalism, which existed before the Great Depression of 1929-1933 [6, 7].

The US futurologist, economist and sociologist A.Toffler reviews the formation of the human society in the context of a coherent development and interaction of three waves in his book "The third wave" published in the 80s of the twentieth century. The first two waves, which are agricultural and industrial civilizations, were followed by the new wave estimated as the establishment of information economy [5]. 
Unlike A.Toffler, Y.Masuda focused on the distinctive features of the information society concept, which is computer technology, mass production of cognitive information, technology and knowledge, cutting-edge area of the economy that is intellectual production, and the realization of the time value, which is the ultimate goal of the new society. In this regard, the French philosopher and sociologist A.Touraine has a different concept. So, he associates the transition of human activity from one type of society with the "societal type" category, where the variables motivation is observed in the circle of sociological transformations from trade to production, production to communication, from one type of culture to another and so on. are monitored. Well-known US sociologist, prominent politician and statesman Zbigniew Brzezinski (1928) justifies in his theory of technotronic society that the civilization entered a new stage of development not due to the social revolutions, but scientific and technical progress. He shows that the quality leap entered the Technotronic Era by means of agricultural industry. Computer, machines and cybernetic systems play decisive role here. And the science performs the main function. Consequently, information technology is the main driving force in the community concepts offered by A.Toffler, Y.Masuda, A.Touraine, and Z.Brzezinski [3, 5, 8, 9].

Modern information society is impossible without the certain resource potential. And this potential contains information products and services.

Several key resource types, which have already turned into classic economic categories, are known in modern industrial society, where most of material forces are directed to production. These types are material, labor, financial and energy resources, each of which has its own purpose. Thus, the process of production of material resources intended for use in public employment act as a set of themes. Natural resources used by the community for the people's material and spiritual needs of the facilities, processes, and natural conditions, labor resources in the community to work with the people in general and professional knowledge, financial resources at the disposal of state funds or commercial structure and, finally, energy resources, energy It covers resources.

The information society mainly focuses on the information resources. Although these resources were available before, they were considered neither economic nor any other category. They were not defined, as well. Information resources became the basic concepts of the society most spoken about during the transition to an information society. And numerous scientific works have been published; different opinions and views have been expressed on the matter so far $[10,11]$.

According to the recent definitions information resources are interpreted as the separate documents and the document sets of libraries, archives, funds, data banks and other information systems. In other words, information resources are characterized as the knowledge designed for the social use by the people and registered in the carriers. And this knowledge is materialized as the document, database, algorithm, computer applications, as well as works of art, and literature $[12,13]$.

Information resource is also the base to create information products. In fact, any information products reflect the manufacturer's information model. However, it is based on the idea of of the manufacturer about a specific subject area. So we can conclude that the information product is the outcome of human intellectual activity saved in any physical carrier as documents, articles, summary, software, books and so on. [11].

The service is the result of non-manufacturing activity designed to meet the needs of person, entity or organization to use different products. It is an intangible form of economic activity, which directly provides the personal needs of the members of society, households, and various types of enterprises, associations and organizations, as well as the social needs of society as a whole. Services are classified as different types of transportation, communications, construction, finance, banking, insurance, logistics, royalties and license fees, government visits, 
personal, cultural, recreational and business services [2.11]. Meanwhile, information service is measured in terms of originality and modernity.

Information services are characterized by the acquisition of information products. Thus, the provision and acquisition of information products are carried out through the information services [14]. in the narrow sense, Information services are understood as a service obtained with the help of a computer. Nevertheless, it is more comprehensive and broader notion.

All above mentioned that is information resources, products and services generally reflect the potential of the information society. Unfortunately, this potential is not realized in all aspects with the same efficiency.

\section{Digitization of information and communication technologies and services}

Information society is increasingly replacing post-industrial society being formed as a system dealing with the implementation, processing, protection, and production of information rather than the processing of the materials. These processes have been driven by the digital revolution caused due to the rapid development of information and communication technologies (ICT) in the fields of radio techniques, microprocessors, and computational techniques, and a number of social sciences. As a result, the technical means and methods have formed the information industry, i.e., a comprehensive industrial network related to the production technology of new knowledge and associated infrastructural systems. Currently, this industry is more deeply penetrating all sectors of public life in the background of the diversification of information society technologies. However, appropriate regulatory authorities have realized institutional, organizational and structural reconstruction $[15,16]$.

ICT is understood as a set of technologies that provide the processing and exchange of information. ICT includes microprocessors, hardware and software, as well as computing equipments, installations, and modern technologies of development, collection, storage, and transmission of electronic information. This comprises computers, software, network infrastructure, and other electronic communications. In this regard, ICT is of both economic and social content. In particular, it should be noted that the resolution of the UN General Assembly dated December 20, 2002, No. 57/295, on "The use of information and communication technologies for development" focuses on these issues, and the impact of ICT on all spheres of the social and economic life [17,19].

Being distinguished for its multiplicative effectiveness the ICT sector has a significant share of world GDP as the main driving force of global socio-economic development in the modern era. Researches show that the rapid growth of ICT occurred in the times of crisis of classic bureaucratic system of governance in developing countries in the 60-70s of the twentieth century, and the ineffectiveness of the times caused the formation of numerous controversial concepts. The of concepts New Public Management (NPM) and "Good Governance" are more distinguished and still applied [18].

"The concept of new public management" includes the attributes that focus on the improvement of the efficiency of state institutions, wide use of management tools in the market, consumer-oriented services, structural changes and appointment of authorities. "The concept of good governance" is associated with the components, such as participation of the citizens and the dialogue with the state, the supremacy of the law, sensitivity of the state institutions to the needs of the citizens, the compromise tendency - to follow the interests, justice - improving the personal welfare of the citizens, effectiveness, mobility and strategic reviews [19].

At the crossroads of the twentieth and twenty-first centuries a new electronic format of governance of the economic and authoritative relations between the state and the citizens has entered our lives. As one of the key elements of the modern information society, an "egovernment" is described as the process of automation of public service delivery" of a constitutional state. The World Bank defines the "e-government" as the means of increasing the 
government efficiency, economy and transparency, and providing public control through the use of ICT. In addition, Gartner Group, specialized as a research and consulting company in the market of information technology, identifies the "e-government" as a the changes in domestic and foreign relations of the public authorities with the use of modern mass media, technical facilities, and the Internet for the optimization of service delivery, and the increasing of the participation in the public administration and domestic processes [20, 21].

The government plays a key role in the transition into the era of the information society. Its capabilities in this area are very high. The most powerful mechanism here is the e-government infrastructure. The full transition to the e-government infrastructure will ensure increasing the competitiveness of state institutions, deepening the reforms, and making the economic progress more efficient and sustainable. With the development of ICT the functionality of the egovernment, which is based on the "single window" principle, will be an increased. New Web 2.0 technology is more widely used here. The technological achievements also expand the opportunities of the political communication, and lead to more advanced forms of integration of the triad of government-citizen -business. The complete implementation e-government is the most important mechanism for the transparent functioning of the government structures.

The new service phenomenon that is the e-government has a number of objectives. These objectives are providing integrated delivery of the Internet services to the citizens, eliminating the information inequality, providing lifelong education and learning opportunities to the people, contributing to the development of the economy, drafting out the laws, which isolate the time barriers, developing the management of forms to guarantee the participation of the citizens and so on. The other objectives of e-government include the optimization of the delivery of the government services to citizens and business entities, increasing the level of the participation of the voters in governance and management, supporting and enlarging self-service opportunities of the citizens, increasing their skills and technological awareness, facilitating the factor of geographic location, and other components.

E-government should not be regarded as a supplement or analogue to the traditional government. So, it defines a new system of mutual relations to improve the efficiency of public services actively using ICT. This development is reflected in the improvement of the economic and government relations between the state and citizens. The electronic turnover of documents, payment of taxes, statistical reporting via the Internet facilitates the companies to comply with the legislation, and increases their efficiency. However, in order to increase the efficiency of the public services this system should be improved and the number of deliveries should reach the optimal and their quality level should be increased. About three hundred people in the European Union by the use of the service as a standard digitizing and highlights. It increases the activity of optimality of citizens and businesses, put forward as a condition of sustainable economic and social development $[19,21]$.

E-government, which is one of the key elements of the information society in the modern era, functions as an improved innovative mechanism that strengthens the activities of the governments, and increased their efficiency. The trends in this direction penetrate all spheres of life, and the importance and role of the e-government in the development of ICT is increasing. It turns into one of more effective methods in the fight against corruption and bureaucracy, as well as in improving the transparency and quality of official structures of public administration. As a new institutional system, e-government contributes to the establishment of "government-citizen", "government-society", "government-business" relations [21, 23]. Its social efficiency and impact on the development of business environment, and being a multifunctional ICT product opens up a wide range of research in this area, as well.

Practice shows that high rate of development of ICT always leaves behind the process of normalization in their application. At the same time, the budget guidelines limit the e-government initiatives. Therefore, a number of economically developed countries establish certain funds. 
Thus, the government provides not only more effective and less costly administration, but also encourages the radical change in the relationship between the government and the public. As a result, this phenomenon improves the democratization in the country and increases the responsibility of the government for the people. The application of e-government in the country reduces the concerns and attenuates political confrontation by harmonizing the relations between the community and the government through the constructive electronical dialogue. Thus, a new management paradigm forms, which is based on the interaction of all structures and institutions of society and the government through the Internet.

The implementation of the objectives of e-government with extensions will give an impetus to the development of the information society. However, a number of problems, particularly identification of citizens, legal relationships in cyberspace, e-taxation and so on are unavoidable. For this reason, every state must establish a new flexible legal framework to trust all types of electronic transactions by maintaining the balance between the economic development and ensuring the confidentiality of information.

\section{Development trends of the information society in Azerbaijan}

As in all spheres of social and economic life in Azerbaijan, a rapid development in the field of information society building is also observed. This development originates from the National Strategy for the development of information and communication technologies in the Republic of Azerbaijan (2003-2012 years) adopted in 2003, and aimed at stimulating the democracy in the country with the widespread use of ICT and at ensuring the transition to the information society by the national leader Heydar Aliyev. As the result of the purposeful policy of the President Ilham Aliyev for the development of ICT, the transition to an information society in the country has entered a new phase. With the execution of the State Program (Electronic Azerbaijan) for the development of Communication and information technologies in the Republic of Azerbaijan in the years 2005-2008 and 2010-2012, an essential and important ICT infrastructure has been formed in the country. As a result, GDP in this sector has increased by 3 times in the last 7 years, and Azerbaijan left behind many developed countries according to the relevant measures [24].

Statistical surveys show that $10 \%$ of the development of ICT contributes to the $1 \%$ of the development of the economy. Therefore, the development rate in this area in Azerbaijan is considered to be more successful. Thus, the growth rate in the country is more than its partners worldwide by 2-3 times. The work done for the development of ICT in the country has attracted the attention of global rating agencies, and the country has been able to gain high positions for "ICT Development Index", "Technological Readiness Index", "Importance Index of ICT for the government for the Future," "Network Readiness Index", "Global competitiveness index" and "Rate of application of the innovations" in a very short period of time. For the further achievements the year of 2013 was announced a "Year of information and communication technologies" in Azerbaijan. Along with the implementation of organizational works, the action plan approved for this purpose aimed at improving the ICT capacity, and developing the human potential and information society building [25].

To increase the efficiency of ICT sector there has been established the State Fund for Development of Information Technology in the country, Institute of Engineering and Information Technology of "ADA" University, Cyber Security Center, High-Technology Parks and other important institutions. In addition, the ICT sector is supported by the "State Program on the establishment and development of space industry in the Republic of Azerbaijan". Note that the relevant UN committee approved Azerbaijan as the member country and had commitments on the use of the space for peaceful purposes. In 2012, the first telecommunications satellite of Azerbaijan - "Azerspace-1" was launched, and in 2014, Earth 
observation satellite - "Azersky" was put into the orbit. The second communication satellite "Azerspace-2" is scheduled to be launched in coming years [31].

At present, the works implemented for the development of information technology and high-tech sector grows with high rates in the country. In this regard, new institutional arrangements and extensive modernization of the infrastructure is underway. Now, the execution of the National Strategy for the "Development of Information Society in the Republic of Azerbaijan for 2014-2020" has started.

A new body - the Ministry of Communication and High Technologies (MCHT) was established on the base on the Ministry of Communications and Information Technology for the development of ITC in Azerbaijan with the introduction of high technologies. Improving the performance with the new status, the ministry is being carried out comprehensive measures for the production of competitive and innovative goods and services, and for strengthening the capacity of the high-tech sector. In addition, Azerbaijan has established "National Nuclear Research Center" Closed Joint Stock Company for the use of nuclear technology for peaceful purposes, and become a member of the nuclear club [26, 27].

The measures taken for the development of the information society so far have led to great consequences. The scope of Internet users has significantly expanded in the country. National Broadband Internet Development" project with the slogan "optic for every home" ensures the increase in the number of broadband Internet users. According to the statistics, currently, there are over $75 \%$ of Internet users, $60 \%$ of which are broadband Internet users. In addition, the broadcasting is being digitalized in the country.

The expansion and stimulation of ICT products has created favorable business conditions and investment environment. With the consulting and investment support of the State Fund for Development of Information Technology the local and foreign investments have been attracted, new technologies have been integrated to the economy, and the projects and scientific research are being implemented in order to expand the application of innovations. Small and medium innovative businesses are being developed, their production and export capacity has been expanded, the projects for the training of the specialists in the ICT sector are being implemented through the High-Tech Park. A new national Cyber Security Center focuses on ensuring information security, prevention of global cyberattacks, and protection of electronic information resources.

In addition, one of the government's initiatives with regard to communications and hightech sector, supported by the United Nations - Trans-Eurasia Information Superhighway (TASIM) project is being implemented. It should be noted that the project aims at providing the main transit link from Frankfurt to Hong Kong, and connects the biggest information exchange centers of Europe and Asia through China, Kazakhstan, Azerbaijan, Georgia, Turkey, and Germany, as well as Russia, Ukraine and Poland [32].

One of the most important works in the information society building is related to the egovernment project. E-government is a unique state infrastructure to carry out their duties. Its strategy opens up opportunities for the sustainable economic achievements, increasing the country's competitiveness, and for the development of significant social effects. The application of this project enters a new successful phase. Within the framework of the project, e-government portal has been developed, which is based on delivering electronic services to the citizens and the citizens' appeals to state authorities through the portal. Any services are available at www.egov.az. To ensure the development of e-government the infrastructure of electronic signature has been formed and mobile authentication certificates center has been developed. At present, the state registries of state information resources and information systems of personal data, as well as a registry of e-services has been developed and implemented. As a result, the number of electronic services in the country reached 500 . 
The State Agency for Public Service and Social Innovations under the President of the Republic of Azerbaijan has been established to provide the coordination of the activity of state bodies, monitoring and assessment, acceleration of the process of delivering electronic services, and improvement of the management in this field. Azerbaijan Service and Assessment Network ASAN service centers have been established, which provide service delivery to the citizens by the state bodies through the agency. ASAN service is an institution joining various services of separate state agencies with e-government interaction and "one door" principle. Functioning as an operator of e-services registry expands the interaction of the agency with e-government. All of these lead to the costs and time reduction, creating favorable conditions for transparency and personal comfort, and give an impetus to the development of economic and authoritative relations between the state and citizens [28].

In order to ensure sustainable progress in the information society building, telecommunications, especially broadband Internet access and rural infrastructure should be developed and improved, the projects increasing the role and importance of ICT in other sectors of the economy should be adequately implemented, export-oriented production must be stimulated, tax incentives must be applied and customs duties optimized, and profitable fiberoptic infrastructure must be developed. Entrepreneurship in the ICT sector should be supported more, start-up companies implementing innovative projects should be financed, and venture investment should be preferred most.

Therefore, the concept "Azerbaijan 2020: Vision for the Future" is being carried out, which contributes to the building of the new innovative economy. The main target of the concept is to increase GDP by 2 times by 2020. It also focuses on high technology and ICT sector. This concept will provide a transition to an information society by 2020 in the country, and establish knowledge-based innovation-oriented economy, as well as ensure the use of ICT and e-services in the state and local government bodies. Furthermore, it will enable the expansion of activities in the field of information security. As a result, in 2020, the costs of ICT and space industry, the development of traditional and wireless communication network, as well as e-government and the fight against cybercrime are projected to be 3 billion USD. In the future, the costs of the scheduled regional economic zones are predicted to be 500 million USD, and the costs of the development of digital television are expected to be 100 million USD. [29, 30].

Due to all of these measures it will be possible to realize the objectives maximally by 2020. As a result, the country's information economy will grow more rapidly by 2020 . Caused by this the national ICT sector will increase by 5 times, and the revenue will reach approximately 10 billion USD. This growth will be accompanied with the growth of the share of production in ICT sector from $9.54 \%$ (2011) to $25 \%$, while it will be over $10 \%$ in the share of GDP. Meanwhile, average investments in the ICT sector will amount 5-6 billion USD.

\section{Conclusion}

Compared to other resources information is becoming prior and global, covering all areas of human social activity. Information union of the human civilization has been formed and stemmed with the information revolution. The development and rise of the information society has formed a number of theoretical concepts. Though these concepts undertake various directions, their starting and development points are information resources, the diversity and importance of its products and services. In this regard, the formation and development factors of the information society are the information, culture and infrastructure, business and economic environment, government, business, civil society, science and education.

The development of the information society penetrates all aspects of our lives. The economy is getting globalized, and the electronic economy and production is getting automated, at the same time, artificial intelligence is being developed. Information technology is the technological ground for the new society, while its driving force is knowledge that is intelligent 
information resources. Information technology is becoming an essential tool to improve the efficiency of production, and to ensure competitiveness in both domestic and global markets. Information infrastructure, which is an important element of the information processing and dissemination tools, serves as the foundation for almost all information services, combining in the telecommunication networks.

In the information society information is an economic resource, while information sector leads for its growth rate, the number of employment, capital investment and the share in GDP. Information, which acts as the main factor of social progress, is becoming the potential of the society, and defines its existence and nature by all parameters. Information potential of the society provides digitalization of the services system, and gives an impetus to the development of the information economy. The socio-economic content of the information society is enlarged with the expansion of e-government structure, and with the increase in the range of electronic services. This shows that the driving force of the development of society is not material anymore, but information processing. Moreover, material and the product itself are of information nature and serves to increasing its innovations. Thus, in the information society, a man is a carrier of information resources.

The process of building the information society in Azerbaijan is characterized by sustainable development trends. The transition to an electronic system is regarded as an important strategic factor of national economic development. All necessary measures are being taken to make this development more sustainable, the relevant institutional reforms are being realized; its production infrastructure and regulatory framework are being improved and expanded. "Azerbaijan 2020: Vision for the Future" concept is being implemented, which is associated with the development of non-oil sector. And information-based information society building is priority here.

\section{References}

1. Ford M. Technologies that will change the world, M., Mann, Ivanov and Ferber, 2013, p. 272.

2. Dimetyir. Information sphere: society in the telecommunications environment. Nizhny Novgorod: Prestige H; M .: Flint, 2010, p. 156.

3. Massouda E. Information Society as a post-industrial society, Moscow, EKSMO-Press, 2003, p. 448.

4. Galbraith J. The New Industrial State, M., ACT, 2004, p. 602.

5. Toffler E. The Third Wave, M., ACT, 2004, p. 784.

6. Webster F. Theories of information society, M., Aspect Press, 2004, p. 400.

7. Bell D. The coming post-industrial society. Sample of Social Forecasting, M., Academy, 2004, p. 578.

8. Brzezinski Z. Between Two Ages: America's Role in the Technetronic Era, New York, The Viking Press, 1970, 355 p.

9. Manuel K. Information Age. Economy, Society and Culture, Moscow Higher School of Economics, 2010, 608 p.

10. Yemelyanova N.Z. Fundamentals of automated information systems, M., Forum: INFRA-M, 2005, 416 p.

11. Popov I.I. Information resources and systems: implementation, modeling, management, M, TPK "Alliance", 2006, 408 p.

12. Smirnova A.E. The theory of information systems, M., PRIOR, 2009411 p.

13. Utkin V.B., Baldin K.V. Information systems and technology in the economy, MI, UNITY DANA, 2005, $355 \mathrm{p}$.

14. Alguliyev R.M., Mahmudov R.Sh. Ensuring the security issues of information economy // Problems of Information Society, 2013, No 1, pp. 3-13. 
15. Alguliev R.M., Aliyev A.G. Economic characteristics of information technology, Baku, "Elm", 2002, 56 p.

16. Barons V.V. Information technology and business management, M., IT Co., 2006, 328 p.

17. Schmidt E., Koen J. New Digital World, M., Mann, Ivanov and Ferber, 2013, 312 p.

18. www.gartner.com

19. Golobutsky A., Shevchuk O. Electronic Government, M., Knowledge, 2007433 p.

20. Alguliyev R.M., Yusifov F.F. Some current scientific and theoretical problems of egovernment formation and solution // Problems of Information Society, 2014, no 2, pp. 3-13.

21. E-Government: Potential and Practical Use / ed. Ivanova G.R.M., Knowledge, 2009329 p.

22. Korneichuk B.V. Information Economy, Study Guide, St. Petersburg, St. Petersburg, 2006, $400 \mathrm{p}$.

23. Nizhegorodtsev R.M. Information economy. In three volumes. M .: MGU, 2002.

24. http://www.president.az/articles/11157

25. http://www.az.president.az/articles/11694

26. http://www.president.az/articles/5416

27. http://www.president.az/articles/5416

28. http://www.az.apa.az/news/264009

29. http://www.mincom.gov.az/layiheler/ilk-milli-telekommunikasiya-peyki/

30. http://www.mincom.gov.az/media/xeberler/details/9601 